THE MOTIVATIONS TO STUDY AND EXPECTATIONS OF STUDYING OF UNDERGRADUATE STUDENTS IN BUSINESS AND MANAGEMENT

Dr Andy Adcroft

Centre for Educational and Academic Development

University of Surrey

Stag Hill Campus

Guildford

Surrey

GU2 7XH

e-mail: $\quad$ a.adcroft@surrey.ac.uk

Tel: $\quad$ +44 (0) 1483682007

Fax: $\quad+44(0) 1483685119$ 


\title{
THE MOTIVATIONS TO STUDY AND EXPECTATIONS OF STUDYING OF UNDERGRADUATE STUDENTS IN BUSINESS AND MANAGEMENT
}

\begin{abstract}
The purpose of this paper is to examine the relationship between motivations to learn and expectations of learning and to see if there are any differences across students groups based on their choice of degree programme and level of study. Six scales were used from Pintrich et al's (1991) Motivated Strategies for Learning Questionnaire, of which two were adapted for this study, to measure motivations to learn and expectations of learning amongst undergraduate students. Across different levels of study and programmes, 564 responses were collected. The study suggests that there is a correlation between the degree of importance and interest that students attach to their studies, their beliefs about how well they will do and their overall levels of motivation to learn. These relationships vary across different student groups. The study also found that the degree of anxiety about assessment experienced by students was independent of their motivations and expectations and did not differ significantly between any student groups.
\end{abstract}

\section{Introduction}

As part of a wider project and series of studies examining how higher quality learning can be promoted, Entwistle (2002) suggests that the overall quality of a learning experience is determined by two factors. The first of these are related to the teacher and include, for example, "pedagogical subject knowledge and conceptions of teaching" (p.6). The second set of factors are those which are student based and include "experience, knowledge, conceptions and reasons for studying" (p.6). This reflects the work of Linnenbrink \& Pintrich (2002) who see academic success as being a combination of "cognitive skill and motivational will" (p.313) which offers a 
useful summary of much research in this area. The motivation to learn of a student is frequently cited as a determinant of success because it influences learning strategies, efforts and the general degree of engagement (see, for example, Cole et al, 2004, Breen \& Lindsay, 2002 and Lucas \& Meyer, 2005).

Pintrich (2003) asks the provocative question 'what motivates students in the classroom?' There is, unsurprisingly, no simple answer to this question for a number of reasons. Motivation is, for example, a "dynamic, multifaceted phenomenon" (Linnenbrink \& Pintrich, 2002, p.313) and different students will be motivated to learn in different ways (Henderson-King \& Smith, 2006). One common element across much of the literature suggests that motivation to learn is related to an individual's expectations and perceptions of learning; "students who believe they are able and that they can and will do well are much more likely to be motivated" (Pintrich, 2003, p.671). The Expectancy-Value model of motivation suggests that there will be three dimensions to expectations in this context (see, for example, DeBacker \& Nelson, 1999): The expectancy component involves beliefs about how an individual may perform; the value component concerns how important or interesting an activity is seen as being and the affective component concerns how an individual may react emotionally to an activity. Pintrich and De Groot (1990) argue that these three elements offer important avenues for investigation into how and why students may be motivated to learn.

Motivation to learn is, therefore, an important area for investigation and Massingham \& Herrington (2006) suggest that it is also a timely one as there have been significant changes to student motivation over the past 30 or so years whereby students have 
become more instrumental in their learning. In general terms there has been relatively little research on students in higher education and little aimed specifically at students in business and management fields of study. Business and management provides a useful context for this research for two reasons. First, it will start to fill the gap in the literature on motivation as business and management studies has some characteristics which make it different to other disciplines: Breen \& Lindsay (2002), for example, suggest that the discipline studied will impact on motivation in a number of ways because, for example, different disciplines have different pedagogical approaches. BMAF (2007) provide data which suggests that pedagogy in business and management is primarily driven by the large student cohorts which are of a size found in few, if any, other disciplines in higher education. Breen and Lindsay (2002) further suggest that the content of degree programmes will also influence student motivation as choices of degree are based on, for example, academic interest or perceived value in developing a career. BMAF (2007) further suggest that the recruitment of students into business and management is primarily driven by levels of careerist motivations not found in other disciplines. Within this study, therefore, there maybe some interesting results in, for example, extrinsic motivation to study. A number of previous studies (see, for example, Bennett, 2004, Cole et al, 2004, Byrne and Flood, 2007 and Adcroft, 2010) have suggested that students in business and management, especially students studying specialist programmes, frequently have high levels of extrinsic motivation which are driven by career ambitions. The second benefit of using this context is that it provides a useful testing ground for comparing different student groups studying in broadly the same field. Module degree schemes in business and management allow for the identification of different student groups based on, for example, the degree of specialism in their chosen programme of study. 


\section{Theoretical Underpinnings}

The theoretical underpinnings of this paper rest on two related assumptions. First, and reflective of the work of Enwistle (2003), is that a students motivation to learn is a key influence on how that student learns overall. The second assumption is that there is a relationship between the type and level of motivation to learn of a student and their expectations of that learning experience. This reflects the work of DeBacker \& Nelson (1999) who suggest that these expectations of learning will have a number of different dimensions. In making the link between motivations and expectations, this paper considers motivation across two dimensions: Intrinsic motivation and extrinsic motivation. Fagan et al (2008) suggest that intrinsic motivation "refers to doing something because it is inherently interesting or enjoyable" (p.31) which is a common explanation across much of the literature. For example, Walker (2008) discusses it in terms of the satisfaction gained from "the activity itself" (p.290) and Patall et al (2008) explain it as a willingness to engage in an activity "for its own sake" (p.271). Deci et al (1999) explain the components of intrinsic motivation through the psychological need for "autonomy" (the sense of an individual being in control of their own decision making) and "competence" (being able to demonstrate a certain degree of proficiency in a chosen activity) (p.268). Patall et al (2008) develop this further and raise two important issues. First, the importance of choice as "people are more likely to engage in an activity if they believed they had chosen it". Second, "relatedness" and the placing of an activity into the context of the wider goals and expectations of the individual. Shroff et al (2008) focus on three related components to intrinsic motivation: A readiness to engage in activities because of curiosity, a desire to master those activities and an ability to demonstrate competency in those activities 
The counterpoint to intrinsic motivation is extrinsic motivation. Much of the literature in this area focuses on the "performance of an activity in order to attain some separable outcome" (Walker, p.290). Fagan et al (2008) take this one step further and argue that there must be an element of "perceived usefulness" (p.33) to activities carried out. This is reinforced by Vallerand et al (1992) who define it as " $a$ wide variety of behaviours which are engaged in as a means to an end and not for their own sake" (p.1006). As with intrinsic motivation, the constituent parts of extrinsic motivation are as important as the broad definition and Ryan \& Deci (2000) summarise a number of studies by suggesting that there are four dimensions to extrinsic motivation: First, "external regulation" where the individual focuses on rewards and/or punishments that may result from undertaking an activity; second, "introjection" where an activity is undertaken in order to secure approval from others; third, "identification" where the individual begins, consciously, to value the activity and, fourth, "integration" where the outcomes of the activity are congruous with the individuals wider goals (p.61). The literature on intrinsic and extrinsic motivation, therefore, suggests a certain degree of complexity as both concepts are multidimensional in nature and are influenced by a number of different factors. The paper now turns to consider some of these influences through a consideration of expectations of learning.

The Expectancy-Value Model of Motivation provides a useful starting point for the discussion and, at its most basic level, suggests that people will perform better in tasks if they believe that they can do well and be successful in those tasks (Eccles \& Wigfield, 2002, p.110). In the context of student learning, DeBacker \& Nelson (1999) 
examine the relationship between beliefs, values, goals and outcomes and suggest that a students' beliefs about, and values placed on, a learning experience are crucial in determining what objectives they may set for themselves and how this may then translate into achievements. Linnenbrink \& Pintrich (2003) accept that there is a relationship between how well equipped a person thinks they are to do something and their level and type of motivation to undertake that task but suggest that the relationship is not so clear cut; will students be highly motivated to undertake a task they are confident of doing well in or is that confidence the root cause of their motivation? In the wider context of the internationalisation of higher education, Byrne \& Flood (2007) accept the relationship and point out that it is especially significant in influencing how and to what extent students engage with learning. Ferla et al (2009) elaborate on this conclusion and argue that a students perception of their own 'self efficacy' will impact on the degree to which they wish to be challenged, the efforts they may put in, their persistence and how they regulate their own learning.

The impact of how well students believe they will do in their studies has been examined in a number of international and disciplinary contexts. Booth (1997), for example, has identified studies from the UK, USA, Canada and western Europe which discuss this issue and it has also been examined from the perspective of education studies (Abouserie, 1995), mathematics and English (Eccles \& Wigfield, 2002) and history (Booth, 1997). Common to many of these studies is the view that what goes hand in hand with expectations of success is how in control of learning a student feels. Eccles \& Wigfield (2002), for example, suggest a link between expectations and control of learning and point out that "evidence supports this prediction" (p.111). Ferla et al (2009) argue that this matters because the extent to which a student feels in 
control of his or her learning will be important in determining how they approach their own learning, a point reinforced by Heikkila \& Lonka (2006) who emphasise the strong correlation between success expectations and self regulation whereby a student must "take responsibility for his or her learning" (p.101). The difficulties identified in much of the research in this area are in striking a balance between students feeling they will be successful and having the "capacity for self assessment" (Lizzio \& Wilson, 2002, p. 112) which allows them to understand what is expected of them in contributing to that success. Cook \& Leckey (1999) identify this as the central academic challenge faced by students entering higher education for the first time and also point out that, with increasing financial pressures on students from fees and loans, challenges are raised for institutions of higher education around the perceived value of their programmes.

For many, the specific higher education context will also impact on motivations and expectations of studying. Bennett (2004), for example, identifies changes in the UK higher education sector which have led to a significant growth in the diversity of the student population. This diversity, however, is more apparent between institutions than within institutions where post-1992 universities are more likely to have a diverse and non-traditional student body than older universities in terms of, for example, age, entry qualifications and previous family experience of higher education. Briggs (2006) suggests that this old and new university distinction will have an impact across the whole student experience starting with the application process where students applying to new universities are most concerned with entry qualifications and students applying to older universities with academic reputation. In a study on intrinsic motivation, Murphy \& Roopchand (2003) found that there are some subsequent 
differences in the motivations of traditional and non-traditional students. This point in reinforced by Read et al (2003) who suggested that "academic culture is not uniformly accessed or experienced" (p.261) because the growth in diversity of students has not been reflected in a growth in the diversity of academic cultures; students from a traditional background will inevitably find it easier to adapt to traditional academic cultures. A study by Connor (2001) suggested that there are some differences between traditional and non-traditional students in terms of their attitudes to financing their studies, personal confidence levels, expected outcomes and working whilst studying and that these will necessarily impact on their motivations and expectations during their time at university.

In discussing these kind of changes in higher education in the UK, Adcroft \& Willis (2005) suggest that a process of "commodification" (p.386) has taken place which fundamentally changes the nature of the student-university relationship whereby the focus on student learning is much more attuned towards they value they will get from it. This view, supported by Massingham \& Herrington's (2006) suggestion that students are more instrumental than ever before in their learning, suggests that how a student attaches value to a learning experience is crucial to understanding both how they are motivated and their degree of engagement. Husman et al (2004) suggest that this attribution of value will have four dimensions: Utility value (what practical use the student can make of learning); Attainment value (what benefits doing well will bring); Intrinsic value (how interesting a learning experience will be) and Cost (alternative learning experiences foregone). A number of studies have suggested that there is a close link between a students perceptions of self-efficacy and the value they attach to learning. For example, in a study of on-line learning, Artino (2008) found 
that students will feel more motivated towards tasks where the value is apparent and Liem et al (2008) suggest that perceived value is the most important influence on student choices: Students, will pick and choose what they want to master and this will, in turn, have an impact on their overall level of satisfaction and emotional state (Stefanou \& Salisbury-Glennon, 2001).

Pintrich \& De Groot (1990) argue that a core dimension to a student's motivation to learn is the emotional responses they have for different learning tasks they undertake and one of the key elements in this is students asking themselves "how do I feel about this?" (p.34). In determining a student's emotional response to learning, and how that emotional response impacts on motivation, they focus on the issue of anxiety related to assessment. Chapell et al (2005) argue that this is a crucial issue because of the clear links between lower academic performance and high levels of anxiety over assessment. Similarly, Birenbaum (2007) found that the most common determinant of student anxiety was the type of assessment undertaken. This is broadly supportive of a much wider body of evidence which places assessment issues at the heart of teaching and learning. Bloxham \& Boyd (2007), for example, suggest that assessment "shapes the experience of students and influences their behaviour" more than anything else (p.3) and both Brown et al (1997) and Gibbs \& Simpson (2004-5) suggest that assessment is fundamental in shaping the beliefs and behaviours of students in higher education. The paper now turns to consider the extent to which these relationships between motivations and expectations of learning are present amongst undergraduate students. 


\section{Methodology}

The sample for this study was drawn from undergraduate students in the School of Management at the University of Surrey. The majority of these students study for a Bachelor of Science (BSc) degree in Business Management. The BSc in Business Management is a generalist degree programme which requires students to study a broad cross section of subjects. The remaining students in the sample study specialist degrees which are offered in areas such as tourism, hospitality, retail and accounting and finance. Both specialist and generalist degree programmes are between three and four years in duration. Students on a four year programme undertake a Professional Training Year (PTY) after their second year of study in which they spend a year working in industry. Those on a three year programme progress directly to the final year after their second year of study. The instrument for the study was administered on-line and all undergraduate students in the School were invited to participate by email. Reminder e-mails were sent weekly and the survey was kept open for 4 weeks. The method of data collection was primarily determined by the ethical regulations of the University which insist on a clear separation between a student's degree studies and any surveys they may participate in. In practical terms this meant that a paper based survey distributed in, for example, large lectures was not possible even though "response rates for web surveys are lower than those for paper and pencil surveys" (Sax et al, 2003, p. 413). Table 1 provides summary details of the responses by level of study and degree programme.

\section{INSERT TABLE 1 ABOUT HERE}

In total, 564 fully completed responses were received giving an overall response rate of $44 \%$. There is variation in response rate across both levels of study and degree programme. For example, whilst more than 7 in 10 final year students completed the 
questionnaire, only 3 in 10 second year students did so. To a large degree, these response rates are consistent with Sax et al's (2003) study which shows that university students are "responding at lower rates than in previous decades" (p. 411) which means that whilst they may be disappointing they are not surprising. The sample size compares reasonably well to many other single institution studies in this area: For example, a number of studies have drawn conclusions from sample sizes of around 200 or less (for example, Fagan et al, 2008, Husman et al, 2004, Abouserie, 1995 and De Backer and Nelson, 1999) whereas others have had much larger sample sizes such as Breen and Lindsay (2002) with almost 400 respondents and Nurmi et al (2003) with almost 700 . With a sample size of 564 , this paper fits in towards the top end of previous studies. Nevertheless, the issue of non-response bias still remains and the difficulty for this study is that the usual methods of dealing with non-response bias, for example comparisons with known values of the population, are not available: No demographic data such as age, gender or ethnicity was collected on advice from the University's Ethics Committee. The implications of this are two-fold. First, any conclusions drawn from the data must be tentative as generalisability may be an issue and, second, findings of this study need to be examined in relation to findings of previous studies in this area.

In measuring the relationship between motivations to, and expectations of, learning, Duncan \& McKeachie (2005) identified over 50 studies between 2000 and 2004 which make use of the Motivated Strategies for Learning Questionnaire (MSLQ). The MSLQ was originally developed in the late 1980s by Pintrich et al (1991) and has, by and large, been used in three ways. First, it has been used to assess the nature of motivation in different student groups. Second, it has been used to refine 
understandings of different motivational constructs and, finally, it has been used to evaluate the impact of different aspects of instruction on motivation. The primary use of the MSLQ in this study is in making assessments across different student groups and, to this end, the MSLQ offers a "viable means for assessing student motivation" (Duncan \& McKeachie, 2005, p.124). The viability of this is reinforced through the theoretical and empirical developments which created the MSLQ such that it has Cronbach Alpha scores which are "robust" (Pintrich et al, 1991, p.4). In terms of validity, Pintrich et al (1991) point out that the use of the MSLQ across different courses and subject areas has given different results and suggests that through this broad sweep of usage, whilst validity may not be "stellar" it is more than "reasonable" (p.79). This validity is further supported by subsequent studies in addition to those identified by Duncan \& McKeachie (2005) which have all concluded that the MSLQ has good levels of, for example, predictive validity (see Linnenbrink \& Pintrich, 2002, Birenbaum, 2007 and Adcroft, 2010)

The MSLQ is a modular instrument whose scales measure a variety of motivations to learn, expectations of learning and learning strategies and this study makes use of six adapted scales. In measuring motivations to learn, two scales from the MSLQ were used: Intrinsic Goal Orientation and Extrinsic Goal Orientation. Intrinsic Goal Orientation measures the degree to which the student is "participating in a task for reasons such as challenge, curiosity, mastery ... participation in the task is an end all to itself' (Pintrich et al, 1991, p.9). Extrinsic Goal Orientation measures the degree to which a student is "participating in the task for reasons such as grades, rewards, performance, evaluation by others, competition ... engaging in a learning task is a means to an end" (Pintrich et al, 1991, p.10). In measuring expectations of learning, 
the study makes use of four scales: Expectations of Performance and Learning which assesses "expectancy for success and self-efficacy ... includes judgements about one's ability to accomplish a task as well as one's confidence in one's skills to perform that task" (Pintrich et al, 1991, p.13); Control of Learning which measures the extent to which students believe that "their efforts to learn will result in positive outcomes ... outcomes are contingent on one's own effort" (Pintrich et al, 1991, p.12); Task Value which "refers to the student's evaluation of how interesting, how important and how useful the task is" (Pintrich et al, 1991, p.11); Test Anxiety which has a "cognitive and an emotional component ... refers to students negative thoughts that disrupt performance ... affective and physiological arousal aspects of anxiety" (Pintrich et al, 1991, p.15).

The scales used have been adapted in two minor ways. First, given the importance of the measurement of motivation to this study, the two motivation scales have had two additional items added to them. These additional items are all adapted from Pintrich \& De Groot's (1990) study of the relationship between motivation and academic performance which was a forerunner to the development of the MSLQ. The outcome of this is that the balance of each scale is altered slightly. With the Intrinsic Goal Orientation scale, the emphasis is now on the acquisition of knowledge which Massingham \& Herrington (2006) and Shroff (2008), for example, have both identified as being central to intrinsic motivation to study. Similarly, the Extrinsic Goal Orientation scale is now more focused on the external comparison dimension to extrinsic motivation which has been identified as important in a number of studies examined by Ryan \& Deci (2000). The second adjustment is in the wording of different items so that respondents were asked about their motivation to study and 
expectations of studying across a degree programme rather than just a single module. Table 2 presents the items for each of the scales under discussion.

\section{INSERT TABLE 2 ABOUT HERE}

In making any changes to an established research instrument, there is always the danger that the study will be undermined. The rationale for these changes, therefore, is crucial and rests on three points. First, this is not an unusual step in either the use of the MSLQ or in motivation studies in general which often use combinations of established instruments and adapted instruments (see, for example, Murphy \& Roopchand, 2003, Breen \& Lindsay, 2002), Cole et al, 2004 and Nurmi et al, 2003) for the purposes of the "local institution" (Pintrich et al, 1991, p.5). Second, the changes are minor and actually increase the reliability of the two motivation scales across all groups. Finally, the specific changes made for this study are the same as that used in a previous study of the motivations to study of business and management students (Adcroft, 2010). Even though there are precedents for these kinds of changes, the issue of validity remains. The most significant test of validity will be in the results generated by the use of this adapted instrument, in terms of both the individual scales and the relationship between scales, and the extent to which such results remain coherent with previous studies using both the original and modified versions of the MSLQ.

Table 3 presents the Cronbach Alpha score for each of the scales across the different units of analysis. The figures in brackets for Intrinsic and Extrinsic Goal Orientation are the scores for just the 4 MSLQ questions before the addition of the two additional questions. Wonnacott and Wonnacott (1990) suggested 0.70 is the cut off value for being acceptable and for five of the six scales this threshold of acceptability is 
reached. The Cronbach Alpha score for Control of Learning, however, falls short of this requirement by a significant margin and so it has been excluded from the presentation and discussion of results which follows.

\section{INSERT TABLE 3 ABOUT HERE}

All questions were in the form of statements and students were asked to rate each statement on a 7 point Likert scale according to how closely the statement reflects their view of themselves. On this scale, 1 signified that the statement was in no way like the student and 7 signified that the statement was a lot like them. In keeping with common practice when using the MSLQ, each respondent was given a score for each scale which was simply the arithmetic mean of the answers to each question. In addition to these 35 questions, respondents were also asked for information about their studies, specifically what level of study they had reached, which degree programme they are studying and, for final year students, whether or not they had undertaken a PTY.

\section{Findings}

In order to contextualise the evidence on the relationship between motivations to learn and expectations of learning, the paper will first present some general data from the sample. Table 4 presents the mean and standard deviation for each of the constructs under discussion across both the whole sample and a range of student groups. The first point to make is that, across both Intrinsic and Extrinsic Goal Orientation, motivation levels are high with all groups having a mean score of more than 5 from a possible 7 . This suggests that the sample is made up predominantly of highly motivated students and the data further suggests something similar in terms of two of the expectation constructs, Task Value and Expectation of Performance and Learning. 
The data suggests that, regardless of programme of study and level of study, students value highly work that is interesting and relevant to their aspirations and that all student groups have high expectations of what they will achieve. The possible exception to this are students who have not undertaken a Professional Training Year who seem to have lower expectations than other groups. One of the more interesting results from the data concerns Test Anxiety which is consistently lower than the other two expectation constructs and also has a consistently higher standard deviation which suggests a wide spread of Test Anxiety across the sample as a whole and within each student group.

\section{INSERT TABLE 4 ABOUT HERE}

The most important questions for this paper are, first, how significant are the differences in scores for each construct across the different student groups and, second, what are the relationships between the different constructs. In answering the first question Table 5 presents the p-values from an ANOVA test and suggests that there are, at a minimum of $95 \%$ confidence levels, a number of significant statistical differences between some student groups across a variety of constructs. The data shows that there are significant statistical differences between students on generalist and specialist degree programmes in terms of both Intrinsic Goal Orientation and Task Value. In both cases, specialist students score significantly higher which suggests that curiosity and interest are much more important to specialist students than generalist students. Whilst there are no statistically significant differences in any of the constructs between first and second year students, there are significant statistical differences in Intrinsic Goal Orientation and Task Value with final year students: Curiosity and interest are lower the closer students get to the completion of their studies. There is also a significant statistical difference in Expectations of 
Performance and Learning between first and final year students with final year students expecting to achieve less than those in the first year. Whether or not students have undertaken a Professional Training Year also highlights some significant statistical differences whereby students who have undertaken a Professional Training Year have higher levels of extrinsic motivation and expect to do better than students who have not.

\section{INSERT TABLE 5 ABOUT HERE}

In turning to the relationship between constructs, Table 6 presents the results of Pearson's Correlation calculations for the whole sample and the different student groups. For the sample as a whole, there are two relationships with high correlations. The first of these is between Task Value and Intrinsic Goal Orientation (0.6454) which suggests that the degree of curiosity which students have about what they are studying is related to how interesting or important they believe what they are studying is. The second high correlation is between Task Value and Expectations of Performance and Learning (0.5246) which suggests that there is a link between how interesting or important something is seen to be and how well students believe they will do. There are also two lower correlations between Expectations of Performance and Learning and both Intrinsic (0.4720) and Extrinsic Goal Orientation (0.3212) suggesting a relationship between how well students believe they will do and their overall level of motivation to learn. Interestingly, there is no real correlation between Test Anxiety and any of the other constructs across the whole sample.

\section{INSERT TABLE 6 ABOUT HERE}

Within different student groups there are both similarities and differences in terms of correlation. For example, all student groups show a high correlation between Intrinsic 
Goal Orientation and Task Value and all students groups show a correlation between Task Value and Expectations of Performance and Learning although the correlation is weaker amongst final year students (especially those who have undertaken a Professional Training Year) and students on general degree programmes. The correlation between Expectations of Performance and Learning and Intrinsic Goal Orientation is strongest amongst first (0.6344) and second year students (0.5829) but is insignificant amongst final year students (0.2940) (again especially those who have undertaken a Professional Training Year (0.1587)) which suggests that final year students have beliefs about how well they will do which are independent of how curious they are about what they are studying. There is consistency in the data as final year students do show a correlation between their Expectations of Performance and Learning and Extrinsic Goal Orientation (0.5045) suggesting that the final outcome of their degree programme is the overarching focus of many final year students. Test Anxiety seems to be independent of the other constructs with two exceptions: Final year (0.3108) and generalist students $(0.4007)$ where there is a low level of correlation with Extrinsic Goal Orientation suggesting a relationship in those groups between how focused students are on gaining good marks and the degree of nervousness they have about the assessment through which they will achieve those good marks.

The data presented suggests that there are key differences in motivations to learn between students on different programmes and at different levels of study and, for some constructs, there are also differences in expectations of learning. Similarly, there are differences between students who have and have not undertaken a Professional Training Year. There are also relationships between some of the constructs which vary in strength and significance across the different student groups. Of all the results, 
perhaps the most interesting concern Test Anxiety which is, to a large extent, not statistically significantly different between any of the student groups and is independent of all other constructs. The paper now turns to discuss the academic and practical implications of these findings.

\section{Discussion and Conclusion}

Before discussing the main conclusions of this study, it is important and useful to place them into the context of the limitations of the study of which there are three. First, despite a sample size in excess of 550, the sample is drawn from just one university and so wider generalisability may be an issue; robust conclusions can be drawn about the motivations and expectations of students at the University of Surrey but the degree to which these students are typical of wider higher education student populations is open to question; the University of Surrey's student population is, by and large, traditional in nature which means that whilst comparisons between pre1992 universities may be possible it is unlikely that meaningful comparisons could be made with, for example, post-1992 universities. For instance, studies by Bennett (2004), Briggs (2006), Murphy \& Roopchand (2003) and Read et al (2003) have, in different ways, identified differences in the learning environments and personal circumstances of students across the sector which can impact on their motivations and expectations. Second, the data collected is, to use an analogy, a series of snapshots of student motivations and expectations and not a moving picture which means that we must make, not unreasonable, assumptions of typicality in order to judge how students' motivations and expectations change as they progress through their studies. The final limitation is in the lack of reliable data on Control of Learning; the study began with the aim of examining six constructs but during the data collection it was possible to collect reliable data for only five. As a counterpoint to these limitations, 
the study has a high degree of internal and external consistency which adds weight to its conclusions. It is internally consistent because it offers a coherent narrative built on reliable constructs and it is externally consistent because it sits reasonably comfortably with previous research in this area and the narrative is, therefore, coherent with much other research in the field. Against this backdrop, the paper offers three main conclusions.

The first significant conclusion drawn from the data is that there is a relationship between motivations to learn and expectations of learning although these relationships vary in size and intensity across different student groups. The data presented both questions and supports different elements of the established literature in this area. For example, the data only partially supports the conclusion of DeBacker and Nelson (1999) which suggests that a student's motivation to learn will be influenced by expectations of achievement and value and some kind of emotional response. The study suggests that whilst there is a correlation between perceptions of value and intrinsic motivation and between expectations of performance and extrinsic motivation, the emotional construct showed no real correlations with any of the other motivation or expectations constructs. These conclusions more accurately reflect Pintrich's (2003) conclusion that "students who believe they are able and that they can and will do well are much more likely to be motivated" (p.671). These conclusions may offer no surprises but it is still unclear as to the direction of the relationships and determining that direction is beyond the scope of this study. The most obvious practical implication of this is that teaching and learning strategies and approaches need to be developed which reflect student attitudes. As Entwistle et al (2002) and Entwistle (2003) suggest, students need to be engaged through both the 
content and process of their learning experience. This is especially important in a world where the student experience is open to ever more levels of investigation and scrutiny and where engagement is closely linked to student satisfaction (Cook and Leckey, 1999, Liem et al, 2008).

The second conclusion from the data is that different groups of students will have different motivations towards, and expectations of, their learning experiences. Again there is probably little that is surprising in this. For example, the data clearly suggests that students who have chosen to undertake specialist rather than generalist degree programmes will have the highest levels of interest in what they are studying which reflects the established work of Deci et al (1999) and Patall et al (2008). Similarly, the evidence that students become more results focused as they near the end of their studies is a good reflection of the work of Fagan et al (2008), Massingham and Herrington (2006) and Vallerand et al (1992). Where the results of this paper are, perhaps, slightly different is in how the blend of motivations changes over time; the data does not suggest that intrinsic motivation falls as extrinsic motivation increases but rather that students maintain their interest in the subject but develop an additional motivation to do well as they near the end of their studies. The implications of this for practice focus on the need to develop pedagogical approaches which help identify, maintain and, where possible, enhance both the processes and outcomes of higher education programmes. The extent to which it is possible to create such approaches is, again, beyond the scope of this paper but both Breen and Lindsay (2002) and Pintrich and De Groot (1990) are optimistic about the potential of developing pedagogical interventions which shape and manage the motivations and expectations of students. 
In Arthur Conan Doyle's 'Silver Blaze', Holmes is able to make the most useful deductions because the dog didn't bark; something being absent can sometimes be as important as something being present. The absence of any correlation between Test Anxiety and the other constructs combined with the lack of any significant difference in Test Anxiety between student groups is perhaps as significant as any of the correlations and differences which are present. Pintrich and De Groot (1990) suggested that the emotional response of how one feels is an important dimension of motivation but the data in this paper suggests otherwise; with just a couple of exceptions, the degree of anxiety over assessment felt by undergraduate students is something which is independent of both motivations to learn and expectations of learning and is no different between students on different programmes and at different stages of their study. There are both positive and negative practical implications of this. On the one hand, Test Anxiety does not increase even when extrinsic motivation and focus on the outcomes of assessment grows significantly. On the other hand, and more negatively, despite growing experience and familiarity with assessment in higher education, the degree of anxiety felt about them does not diminish. Unfortunately, the nature of this study means that it is impossible to judge how such anxiety influences or determines student achievement but it does suggest that specific and targeted interventions to alleviate anxiety are possible. Across all of the conclusions from this study, more questions are asked than answered which suggests that the main contribution of this paper is not in the discussions it draws to a close but rather the avenues it opens for future investigation. For example, are the findings of this study peculiar to business and management students or would students from other disciplines offer different or similar results? Similarly, how influential has the institution been on the results of this study and would students from other universities 
have the same or different characteristics? Finally, moving from a series of snapshots to a more long term study to track changes in motivations and expectations of a whole cohort of students would seem to be useful.

\section{References}

Abouserie, R. (1995) Self-esteem and Achievement Motivation as Determinants of Students' Approaches to Studying in Studies in Higher Education, volume 20, number 1, pp19-26

Adcroft, A. and Willis, R. (2005) The (un)Intended Outcome of Performance Measurement in the Public Sector in The International Journal of Public Sector Management Volume 18, Number 5 pp 386-401

Adcroft, A. (2010) The motivations to study of undergraduate students in management: the impact of degree programme and level of study in International Journal of Management Education, volume 9, number 1, pp11-20

Artino, A.R. (2008) Motivational beliefs and perceptions of instructional quality: predicting satisfaction with online training in Journal of Computer Assisted Learning, volume 24, pp260-270

Bennett, R. (2004) Students' motives for enrolling on business degrees in a post-1992 university in The International Journal of Educational Management, volume 18 , number 1 , pp25-36

Birenbaum, M. (2007) Assessment and instruction preferences and their relationship with test anxiety and learning strategies in Higher Education, volume 53, pp749-768

Bloxham, S. and Boyd, P. (2007) Developing effective assessment in Higher Education: A practical guide, Open University Press, UK.

Booth, A. (1997) Listening to Students: experiences and expectations in the transition to a history degree in Studies in Higher Education, volume 22, number 2, pp205-220

BMAF (2007) An Analysis of the Findings from the Summer 2007 Survey of Key Teaching and Learning Issues in UK Business Schools, Higher Education Academy Subject Centre for Business, Management, Accountancy and Finance, Oxford Brookes University, UK

Breen, R. and Lindsay, R. (2002) Different disciplines require different motivations for student success in Research in Higher Education, volume 43, number 6, pp693-725

Briggs, S. (2006) An exploratory study of the factors influencing undergraduate student choice in the case of higher education in Scotland in Studies in Higher Education, volume 31, number 6, pp705-722

Brown, G., Bull, J. and Pendlebury, M. (1997) Assessing Student Learning in Higher Education, Routledge, UK.

Byrne, M. and Flood, B. (2007) Exploring the Antecedents of Learning Approaches: A study of international business students in International Journal of Management Education, volume 6, number 2, pp44-62

Chapell, M.S., Blanding, Z.B., Silverstein, M.E., Takahashi, M., Newman, B., Gubi, A. and McCann, N. (2005) Test Anxiety and Academic Performance in 
Undergraduate and Graduate Students in Journal of Educational Psychology, volume 97, number 2, pp268-274

Cohen, J., Cohen, P., West, S. G. and Aiken, L. S. (2003) Applied multiple regression/correlation analysis for the behavioural sciences (third edition), Lawrence Erlbaum Associates, New Jersey, USA.

Cole, M. S., Feild, H. S. and Harris, S. G. (2004) Student Learning Motivation and Psychological Hardiness: Interactive effects on students' reactions to a management class in Academy of Management Learning and Education, volume 3, number 1 , pp64-85

Connor, H. (2001) Deciding For or Against Participation in Higher Education: the Views of Young People from Lower Social Class Backgrounds in Higher Education Quarterly, volume 55, number 2, pp204-224

Cook, A. and Leckey, J. (1999) Do Expectations Meet Reality? A survey of changes in first year student opinion in Journal of Further and Higher Education, volume 23, number 2, pp157-171

DeBacker, T.K. and Nelson, R.M. (1999) Variations on an Expectancy-Value Model of Motivation in Science in Contemporary Educational Psychology, volume 24, pp71-94

Deci, E.L., Koestner, R. and Ryan, R.R. (1999) A Meta-Analytic Review of Experiments Examining the Effects of Extrinsic Rewards in Intrinsic Motivation in Psychological Bulletin, volume 125, number 6, pp627-668

Duncan, T.G. and McKeachie, W.J. (2005) The Making of the Motivated Strategies for Learning Questionnaire in Educational Psychologist, volume 40, number 2, pp117-128

Eccles, J.S. and Wigfield, A. (2002) Motivational Beliefs, Values and Goals in Annual Review of Psychology, volume 53, pp109-132

Entwistle, N., McCune, V. And Hounsell, J. (2002) Approaches to Studying and Perceptions of University Teaching-Learning Environments, Occasional Report 1, ETL Project

Entwistle, N. (March 2003) Concepts and Conceptual Frameworks Underpinning the ETL Project, Occasional Report 3, ETL Project

Fagan, M.H., Neill, S. and Wooldridge, B.R. (2008) Exploring the Intention to use Computers: An empirical investigation of the role of intrinsic motivation, extrinsic motivation and perceived ease of use in Journal of Computer Information Systems, Spring, pp31-37

Ferla, J., Valcke, M. And Schuyten, G. (2009) Student models of learning and their impact on study strategies in Studies in Higher Education, volume 34, number 2, pp185-202

Gibbs, G. and Simpson, S. (2004-5) Conditions under which assessment supports student learning in Learning and Teaching in Higher Education, issue 1

Heikkila, A. and Lonka, K. (2006) Studying in Higher Education: students' approaches to learning, self-regulation and cognitive strategies in Studies in Higher Education, volume 31, number 1, pp99-117

Henderson-King, D. and Smith, M. N. (2006) Meanings of education for university students: academic motivation and personal values as predictors in Social Psychology of Education, volume 9, pp195-221

Husman, J., Derryberry, W. P., Crowson, H. M. and Lomax, R. (2004) Instrumentality, task value and intrinsic motivation: Making sense of their independent interdependence in Contemporary Educational Psychology, volume 29, pp63-76 
Liem, A.D., Lau, S. and Nie, Y. (2008) The role of self-efficacy, task value and achievement goals in predicting learning strategies, task disengagement, peer relationship and achievement outome in Contemporary Educational Psychology, volume 33, pp486-512

Linnenbrink, E.A. and Pintrich, P.R. (2002) Motivation as an Enabler for Academic Success in School Psychology Review, volume 31, number 3, pp313-327

Linnenbrink, E.A. and Pintrich, P.R. (2003) The role of self-efficacy beliefs in student engagement and learning in the classroom in Reading and Writing Quarterly, volume 19, pp119-137

Lizzio, A and Wilson, K. (2002) First year students' perceptions of capability in Studies in Higher Education, volume 29, number 1, pp109-128

Lucas, U. and Meyer, J. H. F. (2005) 'Towards a mapping of the student world': the identification of variations in students conceptions of, and motivations to learn, introductory accounting in The British Accounting Review, volume 37, pp177204

Massingham, P. and Herrington, T. (2006) Does Attendance Matter? An examination of student attitudes, participation, performance and attendance in Journal of University Teaching and Learning Practice, volume 3, issue 2, pp1-41

Murphy, H. and Roopchand, N. (2003) Intrinsic Motivation and Self-esteem in Traditional and Mature Students at a Post-1992 University in the North-east of England in Educational Studies, volume 29, number 2, pp243-259

Nurmi, J., Aunola, K., Salmela-Aro, K. and Lindross, M. (2003) The role of success expectation and task-avoidance in academic performance and satisfaction: Three studies on antecedents, consequences and correlates in Contemporary Educational Psychology, volume 28. issue 1, pp59-90

Patall, E.A., Cooper, H. and Robinson, J.C. (2008) The Effects of Choice on Intrinsic Motivation and Related Outcomes: A Meta-Analysis of Research Findings in Psychological Bulletin, volume 134, number 2, pp270-300

Pintrich, P.R. (2003) A Motivational Science Perspective on the Role of Student Motivation in Learning and Teaching Contexts in Journal of Educational Psychology, volume 95, number 4, pp667-686

Pintrich, P. R. and De Groot, E. V. (1990) Motivational and Self-Regulated Learning Components of Classroom Academic Performance in Journal of Educational Psychology, volume 82, number 1, pp33-40

Pintrich, P. R., Smith, D. A. F., Garcia, T. and McKeachie, W. J. (1991) A Manual for the Use of the Motivated Strategies for Learning Questionnaire (MSLQ), Technical Report Number 91-B-004, The University of Michigan, USA.

Read, B., Archer, L. and Leathwood, C. (2003) Challenging Cultures? Student Conceptions of 'Belonging' and 'Isolation' at a Post-1992 University in Studies in Higher Education, volume 28, number 3, pp261-277

Ryan, R.M. and Deci, E.L. (2000) Intrinsic and Extrinsic Motivations: Classic Definitions and New Directions in Contemporary Educational Psychology, volume 25, pp54-67

Sax, L.J., Gilmartin, S.K. and Bryant, A.N. (2003) Assessing response rates and nonresponse bias in web and paper surveys in Research in Higher Education, volume 44, number 4, pp409-432.

Shroff, R.H., Vogel, D.R. and Coombes, J. (2008) Assessing Individual-level Factors Supporting Student Intrinsic Motivation in Online Discussions: A qualitative study in Journal of Information Systems Education, volume 19, number 1, pp111-125 
Stefanou, C.R. and Salisbury-Glennon, J.D. (2001) Developing motivation and cognitive learning strategies through an undergraduate learning community in Learning Environments Research, volume 5, pp77-97

Vallerand, R.J., Pelletier, L.G., Blais, M.R., Briere, N.M. Senecal, C. and Vallieres, E.F. (1992) The Academic Motivation Scale: A measure of intrinsic, extrinsic and amotivation in education in Educational and Psychological Measurement, volume 52, pp1003-1017

Walker, G.J. (2008) The Effects of Ethnicity and Gender on Facilitating Intrinsic Motivation during Leisure with a Close Friend in Journal of Leisure Research, volume 40, number 2, pp290-311

Wonnacott, T.H. and Wonnacott, R. J. (1990) Introductory Statistics for Business and Economics ( $4^{\text {th }}$ Edition), Ontario, Canada: John Wiley and Sons 